\title{
Coulisses
}

Revue de théâtre

1 | Printemps 1990

Varia

\section{Drames de la vie courante}

Rédaction

\section{OpenEdition}

\section{Journals}

Édition électronique

URL : http://journals.openedition.org/coulisses/1539

DOI : $10.4000 /$ coulisses.1539

ISSN : 2546-9460

\section{Éditeur}

Presses universitaires de Franche-Comté

\section{Édition imprimée}

Date de publication : 1 avril 1990

Pagination : $9-10$

ISSN : 1150-594X

\section{Référence électronique}

Rédaction, «Drames de la vie courante », Coulisses [En ligne], 1 | Printemps 1990, mis en ligne le 04 juillet 2017, consulté le 10 décembre 2020. URL : http://journals.openedition.org/coulisses/1539 ; DOI : https://doi.org/10.4000/coulisses.1539

Ce document a été généré automatiquement le 10 décembre 2020.

Coulisses 


\section{Drames de la vie courante}

\section{Rédaction}

1 Un dimanche après-midi ensoleillé. Salle comble à l'Espace-Planoise. Drames de la vie courante, spectacle signé Philippe Adrien, est une suite de courtes scènes qui s'enchaînent à un rythme soutenu, façon film muet. Les histoires, style romansfeuilletons populaires, sont traitées avec l'esprit caustique cher à Cami, le metteur en scène ayant choisi le mode burlesque des grandes heures du caf'conc et des films de Chaplin. Comme à l'époque du muet, un pianiste, placé hors de la scène, accompagne le spectacle. La musique, en synchronie avec le jeu des acteurs, suit la dynamique de l'action. "C'est éprouvant parce qu'il faut donner toute son énergie pour que le spectacle ait du corps. Il faut de la santé ! À la fin, je me sens complètement vidé » (le pianiste).

2 Pour un tel spectacle, qui exige un public proche, le rapport scène-salle est primordial. «Ce que nous jouons est tellement éphémère que les spectateurs doivent le recevoir dans l'immédiat. Quand le public est très loin, ça ne passe pas " (un acteur). Et ce dixneuf novembre, la salle est bonne. De l'avis même de la troupe, c'est la meilleure salle depuis le début de la tournée. "On a senti tout de suite que le public était chaleureux, qu'il était réceptif à l'humour de Cami. Pour nous, c'est formidable parce que c'est un spectacle qui demande un échange; on ne peut pas le porter seuls » (un acteur). 


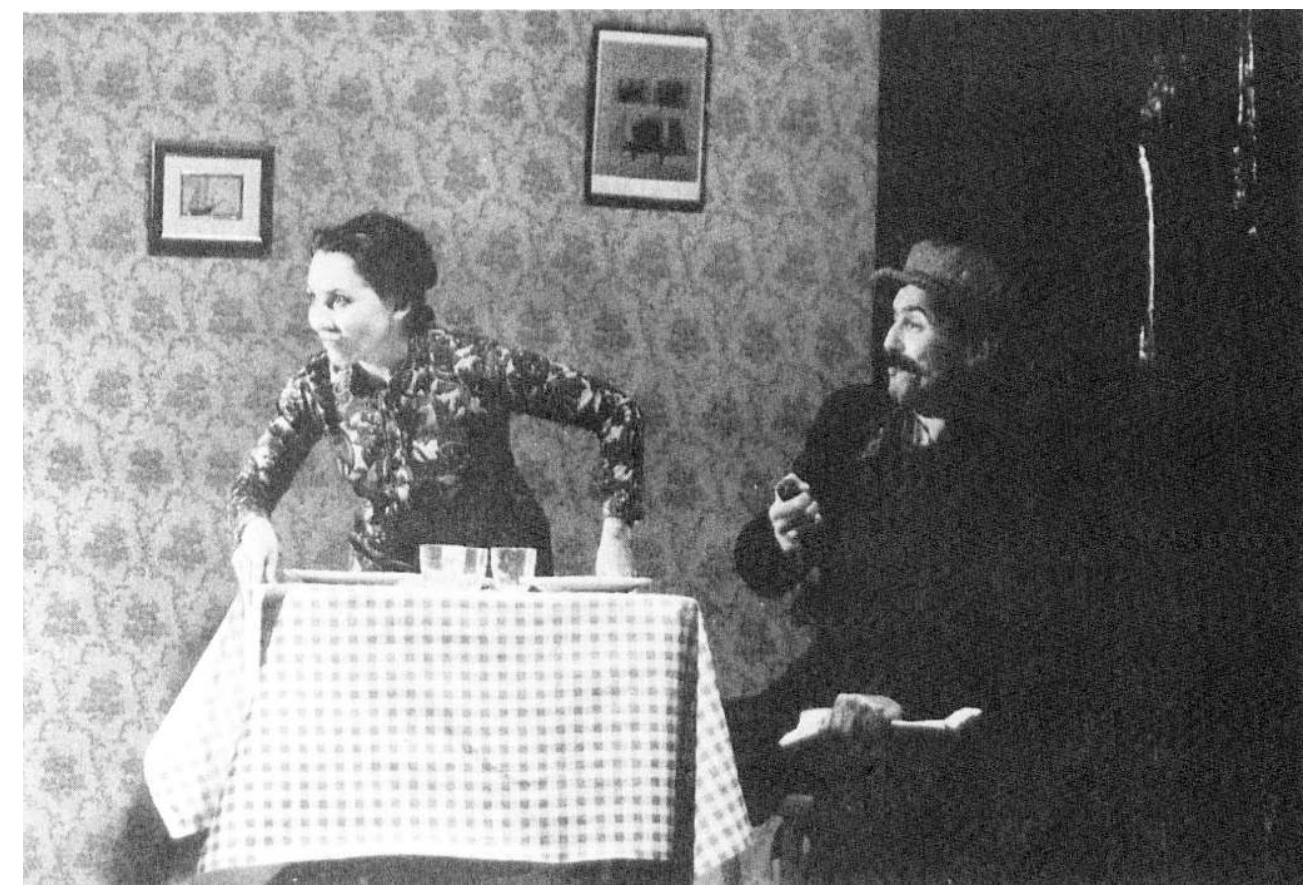

Drames de la vie courante.

(c) Valérie Goy.

\section{Réceptions contrastées}

"C'est un spectacle excellent avec une sorte de génie mécanique du rire; tout est tellement bien huilé que c'est presque un mouvement d'horlogerie. Du grand art. »

"Ça marche par gags mais amenés d'une façon pesante, faussement enlevée. C'est un peu décousu au niveau de la construction avec des scènes parachutées. »

5 «C'est délirant; j'adore cet humour, noir parfois. Ça fait du bien, j'ai aimé le côté complètement loufoque, grotesque, c'est gai, drôle, ça décape. »

6 "Il y a des gens qui riaient mais moi ça me faisait pas rire du tout.»

7 «J'ai pas trop aimé. C'était un peu lourd quand même. »

\section{Enthousiasme}

8 «Le jeu est excellent, le travail corporel en particulier, avec un rythme très rapide. C'est une mise en scène superbe, éclatante. »

9 «L'inspiration est fabuleuse, surtout le travail du rythme. »

\section{Étonnement}

10 «Ce qui me surprend, c'est que ça se joue à l'Espace-Planoise qui est un lieu plutôt culturel et sérieux. On n'a pas l'habitude de voir ça ici. Dommage que ce ne soit qu'une fois. » 


\section{Réaction}

11 «Dire que l'humour est lourd est un non-sens. Ou c'est lourd et alors ce n'est plus de l'humour. Ici, c'est un humour à je ne sais pas quel degré, au cinquième, au sixième degré I II y a des choses qui, considérées au premier degré, semblent lourdes mais quand c'est appuyé à ce point, ça dépasse la lourdeur ; ça devient léger. Il ne faut pas rester au premier degré. » (un acteur)

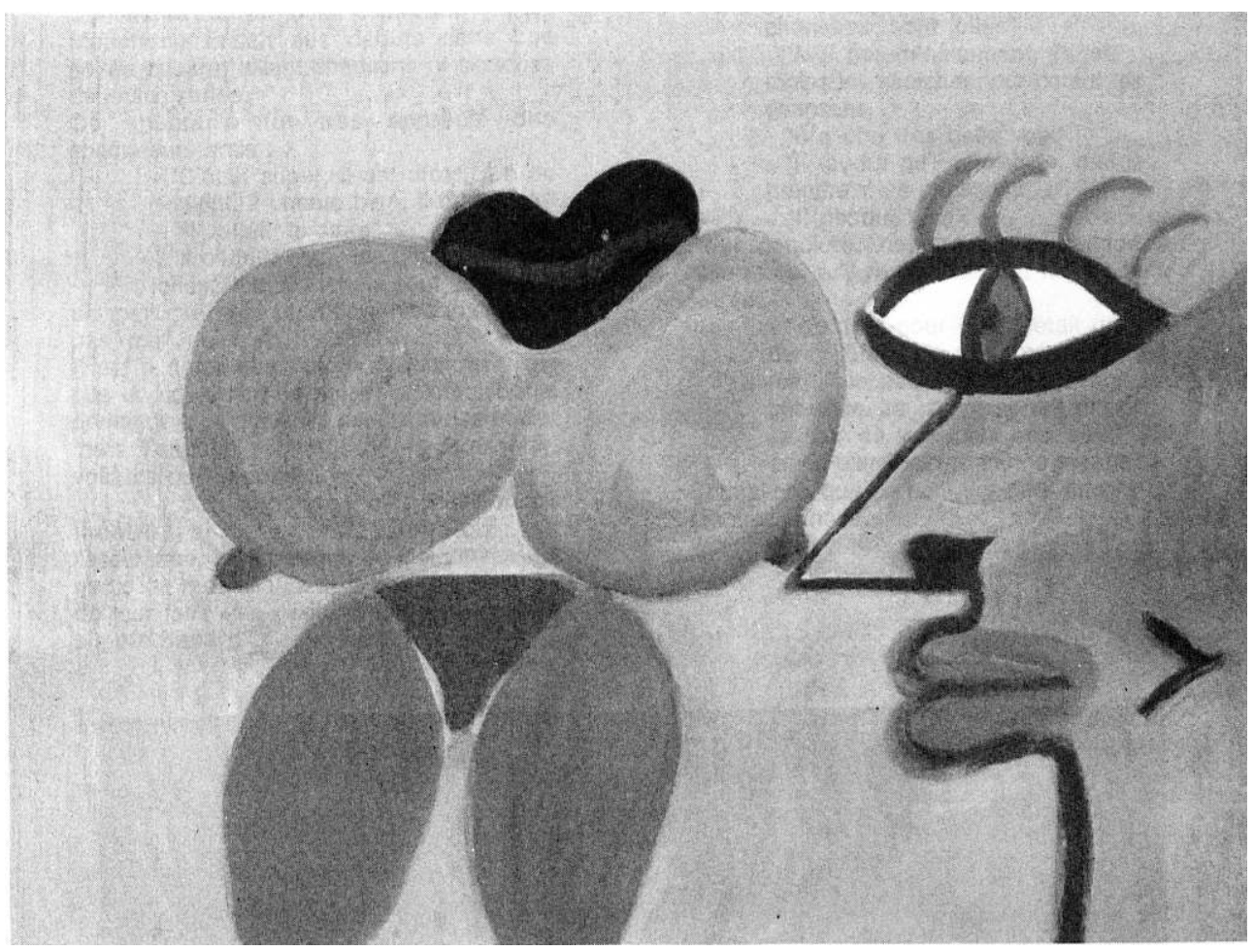

(c) Laurence Gainet. 